\title{
HOW TO CHOOSE THE BEST BLEND USING AHP: THE SIGNIFICANCE OF SENSORY EVALUATION
}

\author{
G. A. Elmasides \\ SEKAP S.A. \\ 10 Militou, Kavala 65404, Greece \\ E-mail: elmasides@sekap.gr
}

\begin{abstract}
This paper aims to give a structured solution to the complicated and knotty problem of selecting the best blend for the needs of any tobacco manufacturing company. The decision in cases like choosing the most appropriate blend -among a number of candidates- becomes an arduous task because the criteria that are taking into account involve measurable (objective) and also subjective or intangible factors. Analytic Hierarchy Process - AHP, is a widely accepted process for establishing priorities in multi-criteria decision problems, incorporating both objective and subjective considerations in the decision process. The implementation of AHP in the specific decision making indicated the suitable blend and also demonstrated the significance of sensory criterion. Finally, the use of the structure is recommended -with slight or extensive modifications- for companies that panel of experts is involved in Quality Control or R\&D, such as Food Industries, Wine Manufacturing and Cosmetic Companies.
\end{abstract}

Keywords: AHP; Sensory Evaluation; Panel of Experts; Tobacco Blends. 


\section{Introduction}

The issue of suitable blend decision is a theme of first importance for every tobacco manufacturing company. Not only because of quality characteristics that blends must comprise or because of the cost effect they induce to the final product, but also due to the fact that the final decision involves intangible -subjective- factors related to the senses (mainly the senses of smell, taste and feel or touch). Obviously, the intangible factors must be combined and associated with tangible and measurable characteristics, so as to take an integrated and -as far as possible- objective decision. This paper illustrates a solution to the critical issue of suitable blend decision (among alternative blends) via the Analytic Hierarchy Process implementation.

\section{Literature Review}

Some of the basic references: Abdallah, F.M., (1970). Can tobacco quality be measured?. Lockwood Publishing Company, New York; Kaplan, R. \& Norton, D. (2008). The execution premium: Linking strategy to operations for competitive advantage. Boston, MA: Harvard Business School Press; Saaty, T. L. (2001). Fundamentals of Decision Making and Priority Theory. Pittsburgh, Pennsylvania: RWS Publications. ISBN 09620317-6-3; Saaty, T. L. (1994). Decision Making - in Economic Political, Social and Technological Environments. RWS Publications, Pittsburgh, PA, U.S.A. ISBN 09620317-7-1.

The present article is the continuation of (author's) former work, and specifically is involved in Strategy Map and Balance Scorecard (BSC), that was developed for the same company. The first Strategic Theme of the Strategy Map ("High Quality Products to the Customers") and also the third Strategic Theme ("Provision of Innovative Products") can involve the proposed structure.

\section{Hypotheses/Objectives}

The objective of our decision hierarchy is already mentioned; is the selection of the most appropriate blend for the needs of the examined tobacco manufacturing company. Four blends are the alternatives that the decision makers (panel of experts) are called to decide the best one (or the most appropriate) among them. The decision making not only indicated the suitable blend but also demonstrated the significance of sensory criterion. The structure can be used -with slight or extensive modifications- by companies that panel of experts is involved in Quality Control or R\&D.

\section{Research Design/Methodology}

The decision regarding the most appropriate blend derived from the presented model to the needs of the specific company. The study is based on sufficient number of previous research, articles and books. This work was supported by the Panel of Tobacco Experts and the Laboratory staff of the examined cigarette manufacturing company. The panel decided for the most appropriate blend (among four alternatives), taking into account four basic criteria: the sensory evaluation, the cost, the chemical indexes and the physical parameters. The four candidate (alternative) blends were compared against twenty-two covering criteria [ 16 for sensory evaluation, 3 for chemical indexes, 2 for physical parameters, and the cost (without subcriteria)]. The related calculations accomplished 
with the help of specific software (MATLAB R2010a). In the current paper there wasn't any occurrence of inconsistency. However, we must comment that, in many cases, a low inconsistency is not the goal of the decision-making process. A low inconsistency is necessary but not sufficient for a good decision. It is possible to be perfectly consistent but consistently wrong. It is more important to be accurate than consistent.

\section{Data/Model Analysis}

The following figure illustrates the Objective ("The Best Blend"), the four main Criteria ("Sensory evaluation", "Cost", "Chemical indexes", and "Physical "Parameters"), the eleven subcriteria and the thirteen sub-subcriteria, with their local and global priorities, in the hierarchical fashion.

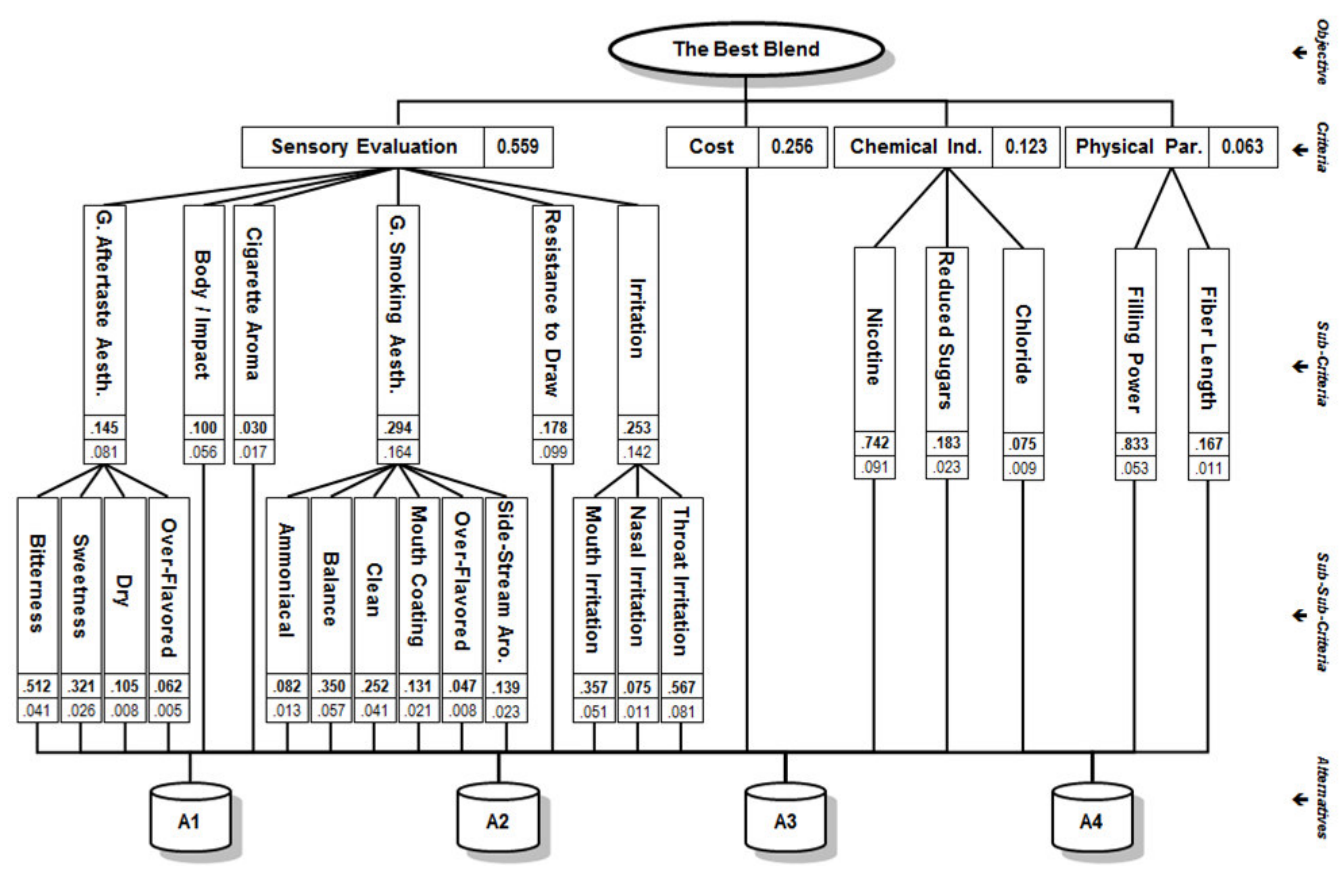

The paper includes seven Pairwise Comparison Matrices regarding the criteria and subcriteria, and twenty-two matrices in relation to the Comparison of Alternatives. The following table illustrates one of them (pairwise comparison matrix of the four main criteria with respect to the Goal).

\begin{tabular}{|c|c|c|c|c|c|}
\hline The Best Blend & $\begin{array}{l}\text { Chemical } \\
\text { Indexes }\end{array}$ & Cost & $\begin{array}{c}\text { Physical } \\
\text { Parameters }\end{array}$ & $\begin{array}{c}\text { Sensory } \\
\text { Evaluation }\end{array}$ & Priorities \\
\hline Chemical Indexes & 1 & $1 / 3$ & 3 & $1 / 5$ & 0.123 \\
\hline Cost & 3 & 1 & 4 & $1 / 3$ & 0.256 \\
\hline Physical Parameters & $1 / 3$ & $1 / 4$ & 1 & $1 / 6$ & 0.063 \\
\hline Sensory Evaluation & 5 & 3 & 6 & 1 & 0.559 \\
\hline$\lambda_{\max }=4.147$ & & & \multicolumn{2}{|c|}{$C R=0.055$} & 1.000 \\
\hline
\end{tabular}

In the following table are illustrated the global priorities of the alternatives regarding the covering criteria, and also, the Overall Priority (The Synthesis Process).

International Symposium of

Washington, D. C. the Analytic Hierarchy June 29 - July 2, 2014 


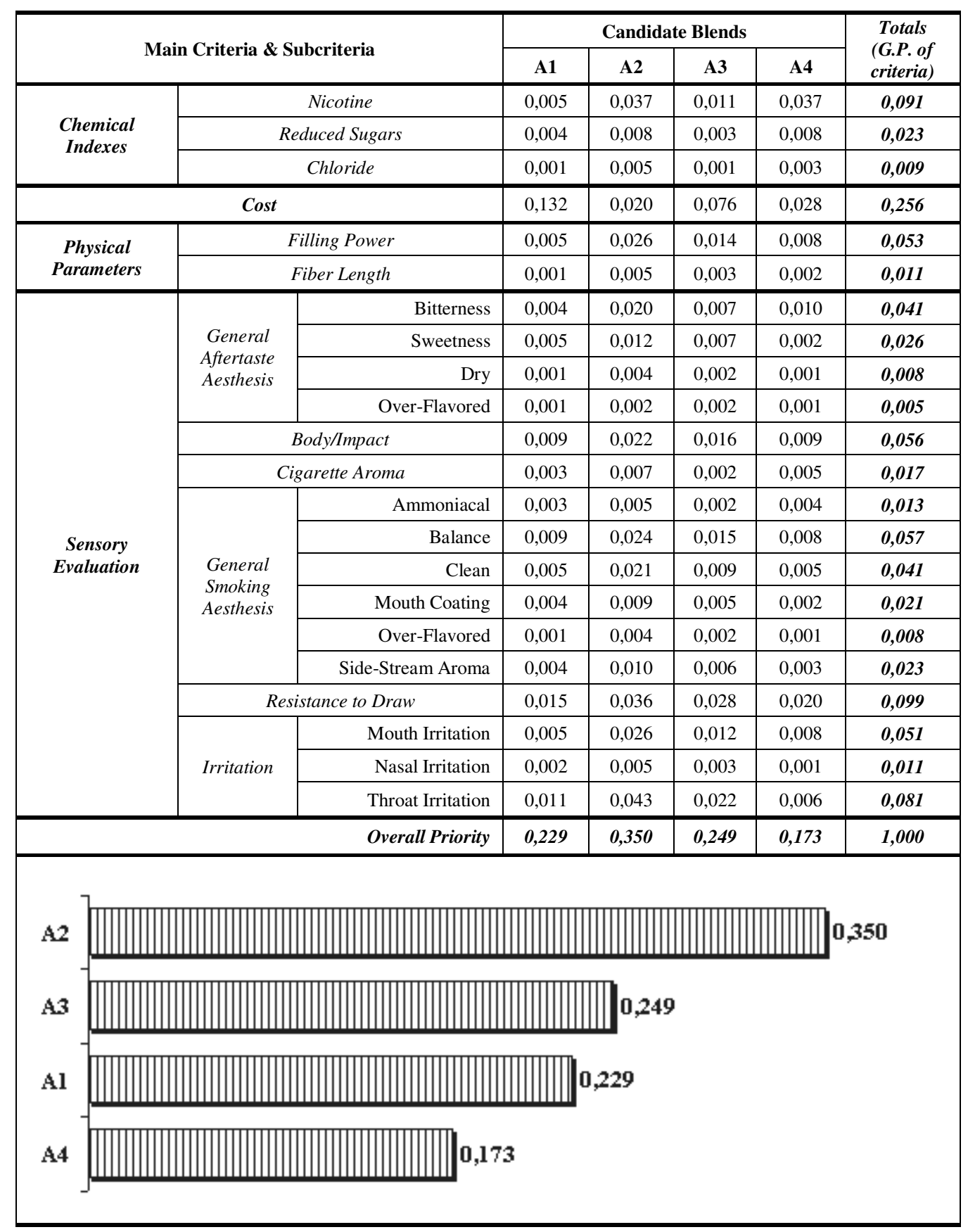

\section{Limitations}

In spite of our attentive effort to do our utmost, we have to confess that we faced difficulties regarding the final decision for the determination and grouping of the criteria that are covered by the "Sensory Evaluation" criterion; in tobacco and cigarette manufacturing literature, there are many (sub-)criteria in relation to "Sensory

International Symposium of the Analytic Hierarchy

Process
Washington, D. C. June 29 - July 2, 2014 
Evaluation". After long-term discussions and "conflicts" we came to the presented model (see above mentioned figure). We are confident that our work will attract the interest of researchers from the same industry (or similar industries) in order to improve the current model.

\section{Conclusions}

Tobacco manufacturing companies face frequently the intricate and also challenging theme of choosing the most appropriate blend among a number of alternatives. The valuable specialty of AHP is the main reason of its implementation for the "Best Blend" decision-making. The presented structured-solution of the best blend selection problem can be a powerful tool for any Tobacco Manufacturing Company, but also, can be recommended to companies that panel of experts is involved in Quality Control or R\&D (Food Industries, Wine Manufacturing and Cosmetic Companies). Additional work is needed in order to verify or improve the proposed model.

\section{Key References}

Abdallah, F.M., (1970). Can tobacco quality be measured?. Lockwood Publishing Company, New York.

Kaplan, R. \& Norton, D. (2008). The execution premium: Linking strategy to operations for competitive advantage. Boston, MA: Harvard Business School Press.

Saaty, T.L. (2008). Relative Measurement and its Generalization in Decision Making: Why Pairwise Comparisons are Central in Mathematics for the Measurement of Intangible Factors - The Analytic Hierarchy/Network Process. RACSAM (Review of the Royal Spanish Academy of Sciences, Series A, Mathematics) 102 (2): 251-318.

Saaty, T. L. (2001). Fundamentals of Decision Making and Priority Theory. Pittsburgh, Pennsylvania: RWS Publications. ISBN 0-9620317-6-3.

Saaty, T. L. (1994). Decision Making - in Economic Political, Social and Technological Environments. RWS Publications, Pittsburgh, PA, U.S.A. ISBN 0-9620317-7-1.

\section{Appendices}

